\section{ULTRASONOGRAPHY: two years of globalization and the achievement of $\mathrm{ESCl}$ status}

JEONG-SIK YU

Editor-in-Chief

ULTRASONOGRAPHY

Two years have passed since the launch of Ultrasonography as an English-language journal. The goal of converting the official language of the journal from Korean to English was globalization of the Korean Society of Ultrasound in Medicine (KSUM) and our official journal [1]. As the editor-in-chief, I would like to summarize the results of our two-year effort toward globalization, to report on the publication of two volumes composed of a total of eight serial quarterly issues, and to provide a perspective on the journal's future.

From late 2013, before the publication of the first English-language issue (Vol. 33, No. 1), the domains for the homepage of our journal (http://www.e-ultrasonography.org) and submission page (http://submit.e-ultrasonography.org) were renewed for English-only sites. Google analytics (https://www.google.com/analytics/web/) has shown a gradual increase in visits to the journal's homepage ever since. In comparison to the proportion of domestic visitors from within Korea, the proportion of visitors from around the world has markedly grown along with the number of visitors' nationalities (domestic, $n=573$; global, $n=1,228$ from 82 different countries in July 2015), although the growth has stagnated a bit during the most recent few months. Through the free mobile applications available on Google Play or the App Store, many readers have downloaded the journal's contents in accordance with the full Open Access policy of the journal. As of the publication of this issue, the journal page of Ultrasonography is the first result of a search for the word 'ultrasonography' via google. co.kr and third via google.com, even though 'ultrasonography' is a general term indicating an imaging technique in addition to a proper noun referring to the title of our journal. We suppose that readers of our journal frequently access the journal content by googling the term 'ultrasonography,' resulting in the most frequent selection of the journal's homepage among search results for this term. This could be influencing the journal's prominent location in Google search results.

The number of articles submitted for publication by authors from outside Korea has sharply increased from $9 \%$ in 2014 to $43 \%$ so far in 2015 . Among published articles, the four issues of 2014 contained only Korean authors, but six out of 40 papers were written by

\section{Jeong-Sik Yu, MD}

Department of Radiology, Gangnam Severance Hospital, Yonsei University College of Medicine, 211 Eonju-ro, Gangnam-gu, Seoul 06273, Korea Tel: +82-2-2019-3510, Fax: +82-2-3462-5472, E-mail: yjsrad97@yuhs.ac

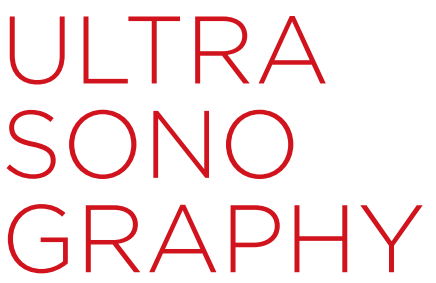

\section{EDITORIAL}

http://dx.doi.org/10.14366/usg.15078 pISSN: 2288-5919 • elSSN: 2288-5943 Ultrasonography 2016;35:1-2

Received: November 28, 2015

Revised: December 7, 2015

Accepted: December 8, 2015

This is an Open Access article distributed under the terms of the Creative Commons Attribution NonCommercial License (http://creativecommons.org/ licenses/by-nc/3.0/) which permits unrestricted noncommercial use, distribution, and reproduction in any medium, provided the original work is properly cited.

Copyright @ 2016 Korean Society of Ultrasound in Medicine (KSUM)

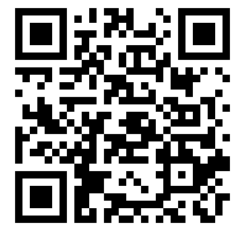

How to cite this article:

Yu JS. ULTRASONOGRAPHY: two years of globali-zation and the achievement of ESCl status. Ultrasonography. 2016 Jan;35(1):1-2. 
international authors in 2015. The first issue (Vol. 35, No. 1) of 2016 will contain 11 articles by authors with eight different nationalities.

The number of citations of Ultrasonography articles is also increasing, and over one hundred citations of articles from our journal were identified on CrossRef (http://www.crossref.org/) or Web of Science (http://apps.webofknowledge.com/) up through November 2015. Considering the limited number of articles published in the early period of our journal (about 40 articles per year), this number of citations looks encouraging. The authors who cited the articles issued in Ultrasonography are affiliated with institutions in 20 different nations, and the majority of them are from the States and European countries.

In addition to the journal's success with attracting international authors and readers, in early November, we were pleased to learn from Thomson Reuters that Ultrasonography is now indexed in a new edition of Web of Science called the Emerging Sources Citation Index (ESCl) (http://wokinfo.com/ media/pdf/S024651_Flyer.pdf), which complements the highly selective indexes by providing earlier visibility for sources under evaluation as part of Science Citation Index-Expanded (SCIE). In addition to the full Open Access policy and early indexing in PubMed (http://www.ncbi.nlm.nih.gov/pubmed? term=Ultrasonography[jour]) for issues beginning July 2014 [2], ESCl could enhance the globalization of Ultrasonography by providing a place for journals like ours: "high-quality, peer-reviewed publications of regional importance and in emerging research fields by key opinion leaders, funders, and evaluators worldwide" (http://wokinfo.com/products_tools/ multidisciplinary/esci/). The articles in Ultrasonography will become discoverable and citable on Web of Science beginning with journal content published in 2015.

We realize that ongoing publication of timely topics in the basic physics, novel technologies, and current clinical issues associated with medical ultrasound is essential to sustain and to enhance the status of our journal toward eventual indexing in more selective databases such as SCOPUS or SCIE, which could, in turn, drive the qualitative and quantitative improvement of Ultrasonography to become a globally leading journal.

ORCID: Jeong-Sik Yu: http://orcid.org/0000-0002-8171-5838

\section{References}

1. Yu JS. ULTRASONOGRAPHY: a new beginning with international open access. Ultrasonography 2014;33:1.

2. Yu JS. ULTRASONOGRAPHY: on the way to becoming an internationally renowned journal. Ultrasonography 2015;34:1-2. 